University of Wollongong

Research Online

Faculty of Law, Humanities and the Arts Papers (Archive)

Faculty of Arts, Social Sciences \& Humanities

$1-1-2016$

'Not in front of the parents!' Young people, sexual literacies and intimate citizenship in the internet age

Mark J. McLelland

University of Wollongong, markmc@uow.edu.au

Follow this and additional works at: https://ro.uow.edu.au/lhapapers

Part of the Arts and Humanities Commons, and the Law Commons

Research Online is the open access institutional repository for the University of Wollongong. For further information contact the UOW Library: research-pubs@uow.edu.au 


\title{
'Not in front of the parents!' Young people, sexual literacies and intimate citizenship in the internet age
}

\begin{abstract}
Clause 13 of the United Nations Convention on the Rights of the Child states that children have the right 'to seek, receive or impart information and ideas of all kinds, regardless of frontiers, either orally, in writing or in print, in art or in any other media of the child's voice'. However, there is one area in which this directive is constrained in various countries by domestic regulations curtailing children's access to information. That area is human sexuality. The arguments for and against children's access to sex education are well rehearsed. In this article, the author pursues a different angle, looking instead at the increasing restrictions placed upon young people's ability to imagine and communicate with each other about sexual issues, particularly in online settings. The advent of the internet and a range of social networking sites have not only enabled young people to access previously quarantined information about sexuality, but also to actively engage in forms of 'intimate citizenship' online. In this article, the author focuses on young people's online fan communities which use characters from popular culture such as Harry Potter or a range of Japanese manga and animation to imagine and explore sexual issues. 'Child abuse publications legislation' in Australia and elsewhere now criminalizes the representation of even imaginary characters who are or may only 'appear to be' under the age of 18 in sexual scenarios. Hence these children and young people are in danger of being charged with the offence of manufacturing and disseminating child pornography. Despite research into these fandoms that indicates that they are of positive benefit to young people in developing 'sexual literacies', there is increasingly diminishing space for young people under the age of 18 to imagine or communicate about sexuality, even in the context of purely fictional scenarios.

\section{Disciplines}

Arts and Humanities | Law

\section{Publication Details}

McLelland, M. (2016). 'Not in front of the parents!' Young people, sexual literacies and intimate citizenship in the internet age. Sexualities: studies in culture and society, 20 (1-2), 234-254.
\end{abstract}


'Not in front of the parents!' Young people, sexual literacies and intimate citizenship in the internet age

Mark McLelland, University of Wollongong, Australia

Originally published online in the Sage journal Sexualities, May 2016, Dol: 10.1177/1363460716645791 Corresponding Author: Mark McLelland, School of Humanities and Social Inquiry, Faculty of Law, Humanities and the Arts, University of Wollongong, Wollongong NSW 2522, Australia. E-mail:markmc@uow.edu.au

\begin{abstract}
Clause 13 of the UN Convention on the Rights of the Child states that children have the right 'to seek, receive or impart information and ideas of all kinds, regardless of frontiers, either orally, in writing or in print, in art or in any other media of the child's choice'. However there is one area in which this directive is constrained in various countries by domestic regulations curtailing children's access to information. That area is human sexuality. The arguments for and against children's access to sex education are well rehearsed. In this article I pursue a different angle, looking instead at the increasing restrictions placed upon young people's ability to imagine and communicate with each other about sexual issues, particularly in online settings. I focus on young people's online fan communities which use characters from popular culture such as Harry Potter or a range of Japanese manga and animation to imagine and explore sexual issues. 'Child abuse publications legislation' in Australia and elsewhere now criminalises the representation of even imaginary characters who are or may only 'appear to be' under the age of 18 in sexual scenarios. Hence these children and young people are in danger of being charged with the offense of manufacturing and disseminating child pornography.
\end{abstract}

Keywords: children, internet, fandom, manga, citizenship, pornography

\title{
Introduction: 'Generational sexualities'
}


Ken Plummer notes that sexuality is a vast and complex set of ideas, practices and symbols and that to fail to take this complexity into account in research results in the portrayal of 'shallow worlds' (2010: 164). ${ }^{\mathrm{i}}$ In a recent article Plummer looked back over four decades of research and activism around issues of sexuality and noted a dimension not always highlighted in sexuality research - the importance of an individual's generational background. Plummer notes how a range of factors, political, legal, cultural, medical and others work together to structure both the embodied sexual experience and symbolic repertoire of each generation. Hence what he calls 'generational sexualities' 'develop distinctive ways of seeing and inhabit different symbolic worlds' (2010: 172). As he notes, 'each generation - born at a specific juncture - confronts the world as it moves through it together in different ways' (2010: 176). He thus calls for a 'generational-age-embodied analysis of sexuality' (2010: 176).

In this article I consider the implications of this generational distinctiveness with regard to young people today, those often referred to as 'Generation Y' or 'Gen Y' (born between the early 1980s to the early 2000s). Gen Y is the first generation to come of age in an environment saturated with information and communication technologies (ICTs) and the use of these technologies plays an important part in young people's identity formation and selfexpression. This new media environment has created 'the possibility for new interactive spaces, and the construction of new social realities and new forms of embodiment' (Young and Whitty, 2012: 22) in sexual as well as other realms of human identity.

Numerous studies have pointed out that digital media have become integrated into daily life, used extensively for education, work and leisure. For this reason, educating young people about both the affordances and risks of these technologies is now a crucial aspect of literacy education (Williams and Zenger, 2012). Indeed, a recent report commissioned by UNICEF noted that 'the media and communication environment is integral to many if not all of children's rights' (Livingstone and Bulger, 2013: 2) and that '[d]rawing the line between offline and online is becoming close to impossible; almost any experience has an online dimension' (2013: 4). Yet, despite the clear importance of understanding the nature of young people's engagement with ICTs, the report questioned 'whether sufficient research currently exists to support evidence-based policy and practice regarding children's rights in relation to internet and mobile technologies' (2013: 4). In particular the report noted that: 
heightened anxiety about young people's ICT use can result in overly restrictive policies that undermine ways in which the internet could empower children with unprecedented opportunities to learn and participate, including in relation to their identity, privacy, sexuality or health (2013: 4).

Today's young people are developing and exploring new ways of negotiating and interacting sexually in online contexts, which Plummer has related to new emerging forms of 'intimate citizenship' (Plummer, 2003: 13-14). Plummer regards 'intimate citizenship' as involving three main aspects, each of which can be related to online activities. These are:

the decisions people have to make over the control (or not) over one's body, feelings, relationships; access (or not) to representations, relationships, public spaces etc.; and socially grounded choices (or not) about identities, gender experiences, erotic experiences (2003: 14). (italics in the original)

Yet, as will be argued below, although the UN's International Convention on the Rights of the Child (CRC) Article 13 contains clear provisions that require states parties to facilitate young people's access to information, one area in particular, information about diverse expressions of human sexuality, remains highly regulated where children and young people are concerned. As Aggleton and Campbell argue:

few countries to date have sought seriously to develop their approaches to sex and relationship education within a rights framework, which raises a number of important questions concerning the extent to which the interests and rights of young people have been taken on board in existing provisions (2010: 293).

One result is a highly confusing regulatory landscape where sexual acts that may be legal to perform by 16 and 17 year olds (who in some jurisdictions are above the local age of consent), for instance, may constitute child pornography if recorded and transmitted digitally. This applies to pictures of a young person's own body -- so-called 'selfies' (Simpson, 2013: 691) as well as text-based descriptions of sexual acts or incitements to perform acts. Less wellknown is the fact that depictions of sexual acts performed by fictional characters who may only 'appear to be' under 18 also may fall foul of child pornography legislation in jurisdictions such as Australia, Canada and the UK, as will be discussed below.

I argue that this new generation of 'digital natives' (Palfrey and Gasser, 2008: 4-5) is at the forefront of a movement 'digitalizing' and 'technologizing intimacies' (Plummer, 2003: 21- 
22) and that an important aspect of this movement involves engaging in a range of sexual fantasy play in an online context. Yet, a lack of grounded research into what young people actually do online, the meanings they themselves attribute to these activities and the kinds of sexualised subcultures that they have created and participate in has resulted in an unwarranted 'diagnostic inflation' of activities designated problematic (Hope, 2015: 344). In many jurisdictions provisions aimed at protecting young people from sexual predation and exploitation can also be used to criminalise and prosecute the sexual self-expression of those under the age of 18. Indeed comparisons have been made between 'juvenile self-sexual [sic] exploitation' and other kinds of apparently self-destructive behaviour such as drug use, resulting in calls for increased police monitoring and prosecution of young people participating in acts defined as 'self-exploitation of minors' (Leary, 2007: 18-26). In this scenario the victim is also the perpetrator and legal intervention is recommended 'to protect these children from themselves' (Leary, 2007: 28). What this approach overlooks, however, is the ways in which young people, girls in particular, are 'complex sexual citizens capable of engaging with media in ways that are both critical of, and complicit with, the ideologies of gender and sexuality forwarded in popular culture' (Egan, 2013: 15). As Hope argues, 'little is written about [children's] rights as citizens . . . rarely is there mention in the e-safety literature of children's rights regarding privacy or freedom' (2015: 346).

I argue that a response which invites increased surveillance and intervention by the state in the sexual expression of the young is out of synch with a new kind of 'generational sexuality' that is developing in online contexts. I also suggest that existing legislation contravenes the spirit of several articles in the CRC, particularly those which encourage states parties to facilitate young people's access to information and self-expression, including in an online environment. The blanket prohibition, indeed criminalisation, of certain kinds of online activities undertaken by those under the age of 18 is arguably not in the 'best interests' of the young people concerned since it does not take into account the 'evolving capacities of the child' when evaluating them (see Buss 2000: 282).

In the discussion below I prefer to use the term 'young people' as a descriptor for the kinds of participants to be found in the online communities I go on to discuss. I do this mindful of Friedenberg who notes that "[n]o language in the world has used the word "child" for persons beyond their early teens' (1974: 21). It has been argued that it was 'the Convention on the Rights of the Child of 1989 which first did away with the distinction between children and adolescents and labelled all minors under 18 "child"' (Graupner, 2004). The term 'child' 
collapses infants and adolescents in their mid-teens - clearly categories of person with very different life experiences and capacities - and 'child' also denotes an air of vulnerability and innocence that is inappropriate for the young people I discuss (see also Hope, 2015: 346; Angelides, 2004a: 149). In this article I am not concerned with pre-adolescent children, but with young people from their early teens through to their early twenties, which research suggests are mostly girls and young women, who are active participants in a number of online 'fan fiction' forums which deal in material with sexual themes. I argue that current child pornography legislation, which encompasses all sexual representations of a person (real or fictional) who is, or may only 'appear to be', under the age of 18 , is out of synch with the rights to freedom of expression and freedom to access information guaranteed by articles in international human rights law.

\section{Young people's sexual self-expression online}

As has been widely noted, public discussion of young people's sexual expression has, since the early 1980s, been framed in terms of 'sex as danger' (Pendleton and Serisier, 2009: 92; Angelides, 2004a; Buss 2000: 288-89). Calls for increased surveillance and intervention of the sexual expression of young people by schools, parents and state agencies have only intensified since the widespread roll-out of internet technology across the developed world in the mid-1990s. Concern has been voiced by the media and policy makers alike about how the internet facilitates the sexualisation of children, particularly regarding the circulation of child pornography. There are also ongoing concerns about the potential risks that easy access to sexually explicit images and descriptions may pose to children. As Sahlfeld points out, "the computer with internet access is both a multifunctional tool that can help you write a homework assignment and one which can deliver violent and pornographic material at the same time' (2010: 205). Understandably, these concerns have resulted in a range of legislative measures aimed at removing, blocking and criminalising the possession of images of under-age sexual activity and abuse.

However, as Lunceford notes, '[t]he assumptions surrounding child pornography - that adults are exploiting children - are challenged by a new generation of youth who seem determined to put themselves, and their sexuality, on display' (2011: 100). As argued in the abovementioned UNICEF report, it is necessary 'to recognise children's agency within the wider agenda of children's rights . . . children themselves are one of a number of actors who 
shape the online domain that children inhabit' (Livingstone and Bulger, 2013: 17). Sexualised content on the internet that depicts or describes under-age characters is not solely produced by adults with nefarious intent but is also created, disseminated and consumed by young people themselves. Indeed, when it comes to concerns over the 'sexualisation of children', 'children and adolescents are no longer merely consumers of this sexual ideology, but also creators of digital content that performs this ideology' (Lunceford, 2011: 99). Young people and adults alike are exploring 'the new intimacies generated in cyberspace' (Plummer, 2003: 21).

Most studies into young people's engagement with sexual themes on the internet have, reflecting adult concerns, been framed in a discourse of 'risk', and few have attempted to engage with young people themselves and discover how they feel about the sexual content that they may encounter via new media (Hope, 2015). Hope, in research in the UK, discovered that in one school 'older students were using the school Internet for online sexual conversations' that the ICT manager found 'frankly obscene' (2010: 695). Yet, as he goes on to note, 'the majority of children get pleasure from taking risks, it offers excitement, an escape from tedium', noting also that overly restrictive internet policies mean that young people are not given chance to learn how to assess and manage risks for themselves' (2010: 698).

Wood has argued that efforts to stop young people accessing sexual content are often based on discourses of childhood 'innocence' and as such these approaches have the effect of 'disavowing the possibility that adolescents are in a process of understanding their own sexualities and often desire access to media that allow them to explore their erotic fantasies' (2013: 46). Simpson notes that 'the law has struggled with the autonomy of the child in sexual matters' (2013: 692) and consequently the agency of young people who choose to actively seek out sexual material and wish to engage with other young people around sexual issues in online forums is overlooked. One consequence is, as Aggleton and Campbell argue, '[the] view of young people as sentient beings, meaning givers and construers of their own reality, is very much at odds with some of the dominant tendencies in policy making today' (2010: 285).

There has, however, been one Australian survey on teen 'sexting' (the exchange of sexual images and texts by smart phone or other electronic device) which involved focus groups with 16 and 17 year olds in an attempt to 'understand the contexts of sexting' through 
engaging with 'young people's perspectives on their everyday practices and cultures' (Albury et al., 2013: 3). This survey found that, contrary to much media discussion of the issue, many young people's experience of sexting took place 'outside the context of abuse, victimisation and harassment' (2013: 3). Albury et al. found that many of the informants were confused about the legislation governing the making and exchange of sexual images of persons under age 18. This was particularly so for 16 and 17 year olds for whom consensual sexual activity is legal in most jurisdictions in Australia. As the report's authors point out '16-17 year olds must navigate sexual practices that can be both consensual and legal but, illegal to visually record' (2013: 4).

In fact in Australia the legal prohibitions are more encompassing than simply regulating the exchange of the kinds of images highlighted in the report. Both state (for example, NSW Crimes Act 1900) and federal (Commonwealth Criminal Code Act 1995) regulations in Australia prohibit material that 'depicts or describes' sexual acts involving a person under the age of 18 - so 16-17 year olds could conceivably be charged with the production of child pornography simply by using a 'carriage service' (that is, a telecommunications device) to express their desires or fantasies to their partner verbally, as an image or in writing (Criminal Code ss 474.19 [1]a).

As some adult stakeholders, who also participated in separate focus groups in Albury et al.'s report pointed out, to only emphasise the 'risk' surrounding teen sexting is problematic given that peer-to-peer communication about sexual issues is part of 'a process of sexual learning' (Albury et al., 2013: 15). Young people do not suddenly become sexual at the age of consent (16 in most jurisdictions in Australia, Canada and the UK) but proceed through various levels of sexual awareness and experimentation (see Angelides, 2004a: 152) in the context of which the exchange of sexualised messages and images might be seen as a 'lesser risk' than face-toface sexual activity by the young people involved. Hence to refer back to the three key characteristics Plummer has defined as central to intimate citizenship, we find that in the virtual environment young persons, particularly in the interstitial stage between age of consent and age of majority are inhibited by legislation from exerting 'control' over representations of their bodies, 'access' to representations of the bodies of others (even their significant others) and 'choices' regarding online sexual self-expression. Indeed, not only do young people not have the right to self-determination in this regard, but their sexual selfexpression, when communicated online in any kind of verbal, textual or visual format can be defined as a criminal act. 
In the context of teenagers' developing sense of sexuality, then, Albury et al. note that current Australian laws de-legitimise young people's right to sexual self-expression. They ask, 'what meaning are we ascribing to young people's sexuality if they are deemed outside of legitimate representation?' (2010: 8). Hence, 'current media and legal discourse ensure erasure of teens' sexual self-representations' (Albury et al., 2013: 22) even though such selfrepresentations, for girls in particular, can be 'an important way to respond to the objectifying media portrayals of women' (Hasinoff, 2012: 11). As Harris has noted, drawing on earlier work by Fine (1988) that pointed to the 'missing discourse of [female] desire' in sex education curricula, many young women and girls avail themselves of websites that offer 'safe and free spaces to speak together about sexuality, beyond the gaze of adults, the state and commercial interests' (2005: 42). These spaces are important, she suggests, because they allow young women to negotiate 'new modes of youth citizenship' which acknowledge female sexual desire (2005: 42). Hence, the manner in which child-pornography laws potentially capture the sexual expression of young people - particularly those over the age of consent but below the age of majority - raises serious concerns around young people's autonomy to develop a sense of 'intimate citizenship'.

As other researchers have noted (Simpson, 2013; Lunceford, 2011), the punitive nature of current laws does not take into account the fact that young participants involved in a range of erotic exchanges via new media do not necessarily consider the activities risky or exploitative. Rather, they are actively choosing (as opposed to being coerced) to participate. Hence, Lunceford concludes that 'although the government has a compelling interest in protecting children and adolescents from sexual predators, the law as it currently stands exposes the fissures between what is considered normal adolescent sexuality and the lived experience of adolescents' (2011: 111). To this extent, the sexting debate, 'has been captured by "policymakers", and fails to take in 'the "reality" of young people's technological lives' (Simpson, 2013: 695).

As Albury et al. $(2013 ; 2010)$ have pointed out, negotiating online erotic exchanges can be an important learning experience as part of the project of developing a healthy sexual identity. Aggleton and Campbell also argue that 'sexual health is (or should be) an affirmative concept, a state of well-being imbued with positive qualities, not merely the absence of those that are undesired' and that 'sexual health must be concerned with the attainment and expression of sexual pleasure, not with the repression of sexual energies and desires or their denial' (2010: 
285). However, unlike other researchers who have looked into online interactions involving the production and exchange of sexual images and narratives concerning actual young people, I focus on young people's engagement with the imagined sexual lives of purely fictional characters, in particular the sexual scenarios that are imagined in the context of young women's fan art and fiction. First, I will outline the child pornography legislation which is concerned with these kinds of fan activities, focusing mainly on Australia, with brief reference to Canada and the UK whose legislation contains many similarities.

\section{Legal restrictions concerning imaginary minors}

Widespread concerns about adult sexual abuse of children and the negative effects of exposure to adult sexuality, particularly in pornography, date back to the 1970s when the feminist movement began to draw public attention to the widespread violence and abuse of women and children that was taking place, especially in families (Angelides, 2004a: 141; Adler, 2001: 211). Early child pornography legislation dating from the late 1970s, such as the Protection of Children against Sexual Exploitation Act passed in the US in 1977, aimed to stop the production and circulation of images of harm and abuse of actual children.

Since the digital revolution of the 1990s, however, there has been a further 'explosion of cultural concern' over paedophilia (Angelides, 2004b) which has seen definitions of child pornography expanded to include 'virtual' (that is, unreal, fictitious, manufactured) images including manga (Japanese comics) and animation (Nair, 2010: 223-232).

In Australia, child pornography is defined in both state and federal legislation. On a Commonwealth level, child pornography material, as defined under the Criminal Code Act 1995, Section 473.1, Subsection 273.1, 'depicts or describes a child engaged in sexual activity in a way that reasonable persons would regard as being, in all the circumstances, offensive' (emphasis added). The legislation thus ties the offensiveness of an act or image in with the legal fiction of the 'reasonable person'. The phrase 'or describes' has been highlighted here, since this has been interpreted to mean that the legislation also applies to purely fictional characters and scenarios, as discussed below.

In New South Wales (NSW), 'child abuse material' is defined under SECT 91FB of the NSW Crimes Act 1900 as: 
material that depicts or describes, in a way that reasonable persons would regard as being, in all the circumstances, offensive:

(a) a person who is, appears to be or is implied to be, a child as victim of torture, cruelty or physical abuse, or

(b) a person who is, appears to be or is implied to be, a child engaged in or apparently engaged in a sexual pose or sexual activity, or

(c) a person who is, appears to be or is implied to be, a child in the presence of another person who is engaged or apparently engaged in a sexual pose or sexual activity.

State law also makes use of the 'reasonable person' as an adjudicator of the material's offensiveness. The phrase 'appears to' is highlighted here as this has also been interpreted as applying to fictional characters.

The first test case regarding purely fictional child images took place in NSW in 2008 in connection with an appeal against an earlier conviction for possession of photoshopped pictures of the child characters from The Simpsons TV show. In his ruling on the appeal Justice Adams stated:

In my view, the Magistrate was correct in determining that, in respect of both the Commonwealth and the New South Wales offences, the word 'person' included fictional or imaginary characters and the mere fact that the figure depicted departed from a realistic representation in some respects of a human being did not mean that such a figure was not a 'person' (McEWEN v SIMMONS \& ANOR [2008] NSWSC 1292, para 41).

This finding is in line with legislation in other Commonwealth jurisdictions such as Canada where R. v. Sharpe (2001) found that the term person 'includes both actual and imaginary human beings' (para 38) and in the UK where the Coroners and Justice Act (2009) states that 'References to an image of a person include references to an image of an imaginary person' (para 65.7). Canadian authorities have been particularly proactive in prosecuting Japanese anime and manga art involving child-like characters (Hudson, 2011), and there have been subsequent prosecutions concerning possession of sexualised cartoon characters in Australia, too (Marcus 2015; Newcastle Herald, 2009). The implications of this legislation are such that, 
as Eiland points out, '[n]o one with comic images in their possession -- which can include viewing them on a computer - can afford not to know the law' (2009: 396). This is an alarming situation, especially given the popularity with young people of all forms of comics and animation (Galbraith 2015; McLelland, 2013; Wood, 2013).

So far the majority of discussion about sexualised representations of young people online has focused on depictions involving actual children, that is, it has looked at the dangers inherent in the creation and circulation of images and descriptions of actual under-age persons in sexual scenarios (Goode, 2010; Ost, 2009; Walton, 2005). This focus aligns with UN sources, which mandate the banning of child pornography to combat the exploitation of children (Maalla, 2009). Researchers have tended to overlook 'virtual' or purely fictional images of children in their discussions, even though the legislation in most western countries has been extended to capture such images. When attended to, the treatment of fictional images is often slight, with little awareness of how the creation and circulation of these images can function in contexts quite distinct from those of paedophile networks.

One example is Goode's (2010) discussion of a range of manga and anime (Japanese comic and animated) representations, particularly rorikon ('Lolita complex', that is young, cute girl figures) and a male equivalent known as shōtakon ('Shōtarō complex' named after the boy hero of a popular animation series). Goode acknowledges that these genres are widely popular in Japan, a fact she considers 'bizarre' (2010: 29), but she makes little effort to understand or contextualise their audiences. It is interesting that, in Goode's account, the 'Boys Love' (BL) subculture, which imagines romantic and sexual interactions between 'beautiful boys', of which shōtakon is a subgenre, is not mentioned, despite the fact that BL is popular among women in Japan (and increasingly internationally) in a similar manner to rorikon's popularity with men (Galbraith, 2011; McLelland and Yoo, 2007). Goode gives a pathologising description of these subcultures, despite citing from a blog where one male fan explicitly disavows any relationship between the ' $2 \mathrm{D}$ [two-dimensional] obsession' and 'RL' (real-life) girls. This distinction between two-dimensional fantasy figures and 'real' persons is explored in detail in the Japanese literature in relation to both men's and women's engagement with sexualised manga and animation characters (see Galbraith, 2015: 205-217 for an overview in English). For Goode, these sexualised manga and animation characters 'hover uncomfortably close to actual child pornography' (2010: 29). This statement, however, is the personal opinion of the author herself and not a finding from the academic literature 
investigating the phenomenon which rather suggests that fans' love for 2D images is 'totally separate from their everyday sexual lives' (Saito 2007: 229). The finding from the Japanese research is that these fictional characters are sexually arousing precisely because of their lack of realism (Galbraith, 2015: 205-217; Saito, 2007: 237; Azuma, 2009: 89). Indeed, Wood makes this point in relation to western girl fans of online 'Boys Love' games deriving from Japan, where girls role play as the 'beautiful boy' protagonists. She notes a number of 'distancing efforts' in the design of the games which function as ways of 'separating the player's identification with her avatar to allow possible pleasure in viewing fantasy sexual scenarios that are non-consensual' (2011: 370).

With the range of different audiences who consume this material in mind, the expansion of child pornography legislation to capture purely fictional representations has been critiqued by a number of legal scholars (Byberg, 2012; Nair, 2010; Ost, 2009: 130-31). Ost, for example, questions the rationale for criminalizing 'pseudo-images' involving sexualised representations of children in cases where the content does not involve manipulation of a real child's image (2009: 130-31). Since in these instances no real child is harmed, the creation or possession of such images is a 'victimless crime' and it is difficult to argue for the regulation of these images on the basis of the harm principle. She does acknowledge that the existence of such images may have add-on effects in other areas of offending, such as encouraging a market for real images, but notes that these arguments need to be balanced with the need for freedom of expression. Given that there is no evidence of a strong connection between the viewing of these images and actual offenses, she suggests that where 'drawings, cartoons or written materials in which child sexual abuse features' the 'behaviour is criminalised purely on the grounds of legal moralism rather than real risk of harm' (2009: 131).

Of particular concern here is the fact that hardly any of the legal scholars working in this area have drawn attention to evidence that potentially the largest number of fictional 'child abuse publications' are created by and for young people themselves. Research suggests that one of the most active cohorts involved in the creation and exchange of this material is teenaged girls and young women (Wood, 2013; Galbraith, 2011; Orbaugh, 2010; Tosenberger, 2008; Thorn, 2004). I choose the term 'potentially' with care since the illegality of an image relies on a court of law adjudicating whether 'reasonable persons' would find the image or description 'offensive'. So far there have only been a small number of prosecutions of cartoon images depicting fictional child characters deemed offensive in Australia. These have involved depictions of the child characters from the animated TV shows The Simpsons 
(McEwen v Simmons and ANOR [2008]), The Simpsons and Pokemon (Newcastle Herald 2009) and Japanese anime (Marcus, 2015). There have also been prosecutions of text-based material, including sexualised stories involving the child characters in The Brady Bunch (Whiley v R, 2010).

Most legislation is, however, thin on detail about what comprises an offensive depiction or act, relying instead on the community standard test which invokes the imagined response of a 'reasonable person' to the material in question (Commonwealth Criminal Code Act 1995 Schedule, 473.1). Schedule 473.4 offers some guidance, including taking into consideration: the standards of morality, decency and propriety generally accepted by reasonable adults; and the literary, artistic or educational merit (if any) of the material; and the general character of the material (including whether it is of a medical, legal or scientific character). The limitations of this approach, however, make it very difficult to predict in advance what kinds of material will contravene local sensibilities since what is offensive is not known until a judge or jury finds that the material has violated community standards.

The reasonable person test's emphasis on offence to the viewer (rather than a clarification of the qualities inherent in the act or object) has the effect of locating the obscene in the interpretation of the viewer - a subjective decision that may not be shared by the communities in which the image in question originated and circulates. As Nair notes, 'what is abhorrent and distasteful to some may be perfectly acceptable for some others' (2010: 231). It is these concerns over the subjective evaluation of the reasonable person test that has led legal studies scholars in the UK to argue that '[c]riminalising what are effectively comics or fantasies constitutes a step too far from the liberal harm-based rationale that underpins the prohibition of images which are records of real sexual abuse' (Antoniou, 2013: 11; see also Nair, 2010).

Furthermore, given that the internet is a deterritorialised communications mechanism that takes little account of geographical or cultural location, it is increasingly unclear whose viewpoint might represent that of the 'reasonable person'. As Burri-Nenova points out, we are undergoing sweeping societal shifts in a globalised world, making modern society 'increasingly homogeneous across cultures' but 'heterogeneous within them' (2010: 105). Engagement with the kinds of online fan subcultures under discussion here results in young people 'developing ideas about literacy and culture that are significantly different than those 
of previous generations' (Williams and Zenger, 2012: 2) as will be discussed in the next section.

\section{Young people 'playing' with sex}

One of the main contexts in which creation and dissemination of potentially infringing material takes place is in the fan fiction and fan art surrounding popular culture products and genres enjoyed by young people, particularly young women (see for example, Wood, 2013; Galbraith, 2011; Orbaugh, 2010; Tosenberger, 2008; Thorn, 2004). As Williams and Zenger

point out, 'popular culture' is a crucial resource that 'young people are appropriating and reusing ... to perform identities and make meaning in their own lives' (2012: 3). As such it could be conceived as a new 'art world' (Plummer, 2003: 78) which breaks down the traditional barriers between cultural producers and consumers.

Much of this user-generated content (UGC), uploaded and shared via massively popular portals including LiveJournal, deviantART, YouTube and Tumblr, is sexual in nature. Unsurprisingly, where female fans are concerned, the main subject of these fan works is 'boys' or young male characters, but less well known (in the mainstream media at least) is that the fantasies envisioned are more likely to be homosexual than heterosexual. Male characters from popular TV shows, movies, books, anime and manga series, and even characters from real life such as the band members of One Direction are 'slashed', that is, they are imagined as part of male 'pairings'. The term 'slash' is a reference to the ' $/$ mark and derives from an early fandom in the 1970s that centred on the Kirk/Spock relationship in Star Trek (Jenkins, 1992). Popular pairings include Harry/Draco (from the Harry Potter franchise), Arthur/Merlin (from the TV show Merlin) and Holmes/Watson (from the various Sherlock Holmes books, movies and TV series). It is important to stress that these online fandoms are neither niche, not difficult to discover. Indeed a simple internet search for information about the regular TV program can seamlessly introduce a browser into the world of fan fiction. Tresca estimates the number of Harry Potter fan stories on the web to be in the region of 750,000 - albeit the majority are not sexual in nature (2014: 36). As Tosenberger notes, 'the sheer number of Harry/Draco stories meant that fan readers-including teenagers-who had never heard the term "slash" were likely to encounter it, and thus more likely to become slash writers themselves' (2008: 192). Indeed, Harry Potter author J K 
Rowling is reported to have been so concerned about children coming across this material that she issued a cease and desist letter via her attorneys to one of the fandom's most prominent websites (Tresca, 2014: 36).

We are not, however, dealing with just textual representations but rather with a range of multi-media engagements with the original material. This includes artwork, and 'repurposed media' such as vids (remixed digital footage) and digitally manipulated photographs known as 'manips' (manipulated images). Although the vast majority of vids (for a discussion see Turk 2011) and manips (for a discussion see Brennan 2013) deal with adult characters, when the face of a child character is spliced onto an adult body in a pornographic pose or setting, this can be classified as 'pseudo child pornography'. Indeed recently in Victoria, Australia, the artist Paul Yore was involved in a court case, charged with the production of child pornography. He had inserted the face of a young Justin Bieber as well as the faces of other child models into a collaged artwork that also contained images from adult pornography (ABC 2014).

A great deal has been written about girls' and women's engagement with 'slash fiction' going back to Henry Jenkins' pioneering work Textual Poachers: Television Fans and Participatory Culture (1992). Slash fiction (and associated fan art) can be seen as examples of 'femantasy' (women's fantasies about male characters). As Pallotta-Chiarolli observes,

[o]verall the various genres of femantasy highlight that as women have gained greater economic power and queer feminist understandings and assertiveness over their sexual desires, commercial demand for the sexualization of men, including 'boy on boy action,' may correlate (2010: 89).

Since such material, when it involves characters under 18, is potentially illegal in Australia and elsewhere, for the purposes of this article it is not possible to link to example sites, discuss specific communities or their activities or cite from texts or artwork. The Specific legislation I have in mind that prevents direct citation is the Crimes Legislation Amendment [Sexual Offences against Children Bill] which prohibits 'describing how to obtain access, or describing methods that are likely to facilitate access, to material (for example: by setting out the name of a website, an IP address, a URL, a password, or the name of a newsgroup)' (my emphasis) (2010: 60). I must stress at this point that I do not myself access any such material but am familiar with it from conference presentations, seminars and discussions with 
colleagues researching these fandoms from Japan and the US. The points made below derive from a close reading of the secondary literature on the topic.

Andrea Wood, looking at 'Boys Love' computer games based on manga and anime series 'aimed at adolescent girls' argues that they offer important opportunities for 'ludic (playful) pleasure' beyond 'normative sexual ideologies' (2011: 355). For Wood it is the all-male cast of these games that is particularly attractive for girls since this allows them to bring male authority figures under their 'sexual control' (2011: 363). Tosenberger notes, in regard to Harry Potter, that 'Potter fandom is an arena in which fans of all ages, genders, and sexual orientations can tell stories to satisfy their own desires'. She argues that 'this freedom is especially valuable for younger fans, whose self-expressions are heavily monitored in institutional settings'. She goes on to stress the positive benefits for young fans who 'are able to tell narratives of sexuality in a space not directly controlled by adults, and do not have to shape their stories to adult sensibilities and comfort levels' (2008: 202). The emphasis on lack of adult surveillance is significant given that the sex depicted in these fan-authored creations certainly moves into a realm likely to be judged 'offensive' for those outside the fandom, especially given the age of the characters. In relation to the Harry Potter amateur comic scene, for instance, Sharalyn Orbaugh points out how 'coercive sex, rape, violence and abjection, make frequent appearances' (2010: 182) but most usually in a 'hurt/comfort' scenario whereby the narrative function of the abuse is to provide an opportunity for one partner in a pair bonding to offer comfort and emotional support to the abused partner.

What has not been discussed much in the mostly supportive academic literature on female fandoms, however, is the fact that a great deal of the 'boy on boy action' generated and exchanged in these forums potentially contravenes child-abuse publications legislation, especially as the law has been framed in Australia, Canada and the UK. Take, for example, the Harry Potter franchise which has generated one of the most popular fandoms to date. The official movie versions are rated $\mathrm{M}$ in Australia. $\mathrm{M}$ for 'mature' is the highest unrestricted rating, meaning that it does not specify a minimum viewing age but advises that the film 'contains material that may require a mature perspective but is not deemed too strong for younger viewers'. Young people, who may initially consume the 'official' Harry Potter texts in books purchased from the store or by viewing the movies on DVD, if they were to follow their interest online, would encounter tens of thousands of fan creations specializing in Harry Potter slash. Research into the fandom has stressed how young fans actively seek out these 
online forums, looking for 'a comfortable niche where they can explore their interests in a more-or-less nonjudgmental environment' (Tosenberger, 2008: 191). This is especially important, notes Tosenberger, 'for young fans, whose desires, and the expressions of those desires, are policed more heavily than are those of adults' (2008: 191).

In the absence of any research pointing to the dangers of young people engaging in these kinds of online fantasy spaces, it is unclear why such material should be covered by childpornography legislation. After all, the 'children' supposedly being abused are fictional, and research suggests (Wood, 2013; Galbraith, 2011; Orbaugh, 2010; Tosenberger, 2008; Thorn, 2004) that those 'abusing' them are on the whole young female fans. Furthermore, the kinds of sexual scenarios and narratives that take place in fan fiction between these fictional characters are clearly not part of real life, nor, on the whole, are they extrapolations or expressions of any actual event that takes place in the official text of the narrative itself. Instead they better fit the 'ludic-based relationships' that Waskul and Martin argue describe fantasy internet sex more generally. They note how 'ludic sex-based relationships ... are free of commitment, reproduction, and other closely connected projects of the self' (2010). Ludic sex is often 'ludic(rous)' and unlike offline sexual relations which emphasise 'civilization, order and stability', the emphasis in virtual sex is on 'incivility, disorder and transgression' (2010) - such as the often violent and 'non-con' (non-consensual) scenarios imagined by the fans. What the law frames as 'child-abuse publications' are, in the context of the communities in which they are generated and exchanged, understood to be a 'ludic' form of self-expression and hence the capture of this material can be seen as an unwarranted ‘juridification of the imagination’ (McLelland, 2011: 467-83).

Hence, I argue that the potential framing of all fictional representations of sexualised child characters as 'child abuse publications' fails to take account of the context in which these texts and images were produced and the uses to which they are put by their audiences. I argue instead that the young fans who engage with this kind of sexualised content in online communities comprised of other fans are engaging in an educative process that is both a normal and natural part of the maturation process. The 'lenses of popular culture' are used by young people as semiotic and rhetorical resources to understand and explore their own developing identities (Williams and Zenger, 2012: 3). For instance, Latham, who has researched the readers of teen fiction dealing in sexual themes, points out that: 
The significance of narrative in the progress of a child's understanding of the world does not end in the juvenile stages but continues in adolescence, as a more mature form of play where an individual understands the 'symbolic representation of what has happened' working through and evaluating feelings and events. In this way the texts that we are studying act as training grounds for a girl or boy to understand their own sexual feelings' (Latham, 2010: 32).

The kind of fan fiction sites under discussion are illustrative of what Alexander and Levine refer to as 'Web 2.0 storytelling'. They note that digital networks and social media are transforming the nature of storytelling, resulting in narratives that are 'open-ended, branching, hyperlinked, cross-media, participatory, exploratory and unpredictable' (2008: 40). Hence, building on the literature that stresses the importance of 'digital literacies' for the developing of positive self-expression for young people (Williams and Zenger, 2012: 5-6; Jenkins et al., 2009: 28-29), I suggest that these online sexualised fantasy spaces could be seen as a safe space to explore and develop 'sexual literacies'. With this in mind, the manner in which the law potentially subsumes these online interactions under child pornography legislation is a serious misrecognition of their actual meaning and significance in the context of the sexual maturation process. Furthermore, the extremely broad scope of the legislation impinges on Article 13 of the CRC in particular which states that young people have the right to 'seek, receive and impart information and ideas of all kinds... in the form of art or in any other medium of the child's choice'. The law also impedes young people's ability to develop new modes of 'intimate citizenship', particularly regarding control over their access to 'representations, relationships ... identities, gender experiences, [and] erotic experiences' (Plummer, 2003: 14).

Given the sheer scale of young people involved in these kinds of fannish activities across all developed nations in multiple languages (a Google search for 'Boys Love' fanfiction generates 247,000 hits and Harry Potter slash fanfiction an astonishing 1,410,000 hits), and the multiple online forums where this sexualised communication takes place, prohibition and criminalisation of this material is unlikely to be an effective way to protect young people from perceived harms. Far more effective would be education programs to provide young people with the digital literacies necessary to negotiate, navigate and avoid problematic content that they themselves might find harmful on the internet. As Huang and Archer argue, 'literacy education aims to equip students to survive in a changing world' (2012: 58). This 
kind of literacy education is already something that happens in the context of online fandom itself since 'fan communities develop their own cultural norms for what is or is not acceptable in fanfiction' (Tosenberger, 2008: 190) and site monitors regulate the interaction which takes place as well as the kinds of material that can be uploaded and shared.

In sum, I suggest that the potential criminalisation of young people's playful appropriation of pop culture characters in online sexual scenarios takes no account of the nature of the interaction that takes place in these online communities and fails to address the educative value these communities could play in a young person's developing sexual identity. As such it can be argued that this blanket prohibition and criminalisation of the playful sexualisation of fictional characters runs counter to several provisions in international human rights law which guarantee to young people access to information and freedom of expression, including in relation to sexuality and freedom to engage in cultural expression.

\section{Conclusion}

The emphasis that international bodies such as the UN and UNICEF have placed upon the need for states to facilitate young people's access to information and self-expression via ICTs is clearly important in today's convergent media environment where 'digital literacies' are key to success in education, work and leisure. The UN Convention on the Rights of the Child makes it clear that the right to 'seek, receive and impart' information is key to a young person's health and developing identity, including their sexual identity. Yet, as Hope points out, dominant policy debates around children and cyberspace, through emphasising a discourse of risk, are 'failing to ask fundamental questions about the rights of young children and youths' (2015: 351).

Although the protection of actual children is paramount (and this imperative is constantly underlined by provisions in the CRC), 'we must avoid unintended consequences of wellintended laws, and keep these laws open to improvement' (Palfrey and Gasser, 2008: 286). Freedom of speech advocates have noted, for instance, that because the Australian, Canadian and UK legislation applies equally to written as well as visual depictions of underage sex, it exceeds, by far, international human rights standards (Nair, 2010: 231; Walton, 2005: 35). There is no research to date pointing to negative outcomes of young people participating in 
these online fan fiction forums where sexual scenarios are explored in relation to fictional characters. Indeed, what research there is tends to emphasise the benefits of such participation, particularly for girls and young women. Unfortunately, given the state of current legislation in Australia, it is not possible for researchers to engage with these fan networks, for fear of coming across infringing material; nor is it possible to gain ethics clearance for projects working with young fans that might uncover criminal activities that require mandatory reporting to the authorities. Yet, if I am right in suggesting, following Plummer (2010), that the kinds of fan forums under discussion are examples of the emergence of a new kind of 'generational sexuality', one that is integrated in unforeseen ways with new media and communications technologies, then this kind of research is key to understanding these new developments.

I suggest that one possible avenue of investigation for researchers is to point out the potentially harmful effects of current legislation on young people themselves and to open up a discussion about how young people might be supported in developing and expressing a healthy sense of sexual identity without fear of criminalisation for these expressions. Ken Plummer's notion of 'intimate citizenship', the boundaries of which are constantly changing and being renegotiated in today's hyper-mediated world, is one model that could be used to start this conversation. In the context of these negotiations, it is imperative that those most affected by the current legislation, young people themselves, should have a role to play in any discussion of their best interests. Yet in Australia, at least, the manner in which the legislation has been framed actually hinders the participation of young people in these discussions, as it brands their online fan activities as deviant and potentially criminal.

\section{References}

ABC (2014) Pornography charges against Paul Yore dismissed 7 October. http://www.abc.net.au/arts/blog/arts-desk/Artist-Paul-Yore-acquitted-of-pornographycharges-141001/default.htm (accessed 7 September 2015).

Adler A (2001) The perverse law of child pornography. Columbia Law Review 101(2): 209273.

Aggleton P and Campbell C (2010) Working with young people: Towards an agenda for sexual health. Sexual and Relationship Therapy 15 (3): 283-96. 
Albury K, Crawford K and Byron P (2013) Young People and Sexting in Australia: Ethics, Representation and the Law, Kensington: University of New South Wales.

Albury K, Funnell N and Noonan E (2010) The politics of sexting: young people, selfrepresentation and citizenship. Australia and New Zealand Communication Association Conference: Media, Democracy and Change, 7-9 July 2010, Canberra. Available at: http:www.anzca.ner/conferences/conferences-papers.html (accessed 16 June 2014).

Alexander, B and A. Levine, (2008) Web 2.0 Storytelling: Emergence of a New Genre, EDUCAUSE Review, vol. 43, no. 6 (November/December), available online: http://www.uh.cu/static/documents/RDA/Web\%202.0\%20Storytelling\%20c.pdf Angelides S (2004a) Feminism, child sexual abuse and the erasure of child sexuality. GLQ, 10(2): 141-77.

Angelides S (2004b) Paedophilia and the misrecognition of desire. Transformations, issue 8. Available at: http://www.transformationsjournal.org/journal/issue_08/article_01.shtml (accessed 16 June 2014).

Antoniou A (2013) Possession of prohibited images of children: Three years on. Journal of Criminal Law 77 (337):1-37.

Azuma H (2009) Otaku: Japan's Database Animals translated by Jonathan E. Abel and Shion Kono. Minneapolis: University of Minnesota Press.

Brennan, J (2013) Not 'from my hot little ovaries': How slash manips pierce reductive assumptions. Continuum: Journal of Media and Cultural Studies 28 (2): 247-64.

Burri-Nenova M (2010) User created content in virtual worlds and cultural diversity. In Graber C B and Burri-Nenova M (eds) Governance of Digital Game Environments and Cultural Diversity. Cheltenham: Edward Elgar, pp. 74-112.

Buss D E (2000) How the UN stole childhood: The Christian right and the international rights of the child. In Bridgeman D and Monk D (eds) Feminist Perspectives on Child Law. London: Cavendish Publishing, pp. 271-94.

Byberg J H K (2012) Childless porn: A victimless crime?' Social Science Research Network. Available at: http://papers.ssrn.com/sol3/papers.cfm?abstract_id=2114564 (accessed 13 December 2013). 
Crimes Act 1900. Available at: http://www.austlii.edu.au/au/legis/nsw/consol_act/ca190082/ (accessed 16 June 2014).

Crimes Legislation Amendment [Sexual Offences against Children Act] 2010 (NO. 42, 2010) - SCHEDULE 1. Available at:

http://www.austlii.edu.au/au/legis/cth/num_act/claoaca2010544/sch1.html (accessed 16 June 1024).

Criminal Code Act (1995). Available at: http://www.comlaw.gov.au/Series/C2004A04868 (accessed 16 June 2014).

Coroners and Justice Act (2009). Available at:

http://www.legislation.gov.uk/ukpga/2009/25/contents (accessed 16 June 2014).

Egan D (2013) Becoming Sexual: A Critical Appraisal of the Sexualization of Girls.

Cambridge: Polity.

Eiland M L (2009) From cartoon art to child pornography. International Journal of Comic Art 11 (2): 396-409.

Fine M (1988) Sexuality, schooling, and adolescent females: The missing discourse of desire. Harvard Educational Review, 58 (1): 29-53.

Friedenberg, E (1974) The Vanishing Adolescent, New York: Greenwood Press.

Galbraith P W (2011) Fujoshi: Fantasy play and transgressive intimacy among 'rotten girls' in contemporary Japan. Signs 37 (1): 211-32.

Galbraith P W (2015) Otaku sexuality in Japan. In McLelland M and Mackie V (eds) The Routledge Handbook of Sexuality Studies in East Asia, Oxon: Routledge, pp. 205-16.

Goode S (2010) Understanding and Addressing Adult Sexual Attraction to Children: A Study of Paedophiles in Contemporary Society. Oxon: Routledge.

Graupner H (2004) The 17-year-old child: An absurdity of the late $20^{\text {th }}$ century. Keynote address at the $8^{\text {th }}$ International Conference of the International Association for the Treatment of Sex Offenders, Athens, 6-9 October. Available at: http://www.graupner.at/documents/IATSO-17yoChild.pdf (accessed 13 December 2013). 
Harris A (2005) Discourses of desire as governmentality: Young women, sexuality and the significance of safe spaces. Feminism and Psychology 15(1): 39-43.

Hasinoff, A (2012) Sexting Panic: Rethinking Criminalization, Privacy, and Consent. Urbana: University of Illinois Press.

Hope, A (2015) Schoolchildren, governmentality and national e-safety policy discourse. Discourse: Studies in the Cultural Politics of Education, 36(3): 343-53.

Hope, A (2010) Seductions of risk and school cyberspace. Australian Journal of Education Technology, 26(5): 690-703.

Hudson L (2011) Why comics get confiscated at the Canadian border (and how to protect yours). Comics Alliance May 17. Available at: http://www.comicsalliance.com/2011/05/17 /comic-books-canada-customs/ (accessed 15 February 2013).

Huang C-W and Archer A (2012) Uncovering the multimodal literacy practices in reading manga and the implications for pedagogy. In Williams B and Zenger A (eds) New Media Literacies and Participatory Popular Culture Across Borders. Oxon: Routledge, pp. 44-60.

Jenkins H, with Purushotma R, Weigel M, Clinton K and Robison A (2009) Confronting the Challenges of Participatory Culture: Media Education in the $21^{\text {st }}$ Century. Cambridge, Mass: MIT Press.

Jenkins H (1992) Textual Poachers: Television Fans and Participatory Culture. London: Routledge.

Latham J (2010) More Sex Please - We Are Post-Millenial British Teen Fiction Readers! An Analysis of the Representation of Sexuality in Differing Genres of Popular Teen Fiction and the Significance of Gender Response to them. Unpublished MA thesis, Birbeck College, University of London. Available at: http://www.bbk.ac.uk/english/our-research/researchspecialisms/Reader_Response_Dissertation.pdf (accessed 13 August 2013).

Leary M J (2007) Self-produced child pornography: The appropriate societal response to juvenile self-sexual exploitation. Virginia Journal of Social Policy \& the Law 15 (1): 1-50. 
Livingstone S and Bulger M E (2013) A Global Agenda for Children's Rights in the Digital Age: Recommendations for Developing UNICEF's Research Strategy. Florence: UNICEF Office of Research.

Lunceford Brett (2011) The new pornographers: Legal and ethical considerations of sexting. In Bruce E. Drushel and Kathleen German (eds) The Ethics of Emerging Media: Information, Social Norma and New Media Technology. New York: Continuum, pp. 99-118.

Maalla, N M (2009) Promotion and protection of all human rights, civil, political, economic, social and cultural rights, including the right to development: Report of the special rapporteur on the sale of children, child prostitution and child pornography, UN General Assembly Human Rights Council, Twelfth Session, Item 3. Available at: http://www2.ohchr.org/english/bodies/hrcouncil/docs/12session/A.HRC.12.23.pdf (accessed 12 December 2013).

Marcus, C (2015) Anime images not a big leap to viewing child pornography: SA judge, 15 August. Available at: http://www.abc.net.au/news/2015-08-12/anime-not-a-big-leap-to-childpornography-sa-judge-says/6691372 (accessed 7 September 2015).

McEwen v Simmons and ANOR (2008) NSWSC 1292. Available at: http://www.lawlink.nsw.gov.au/scjudgments/2008nswsc.nsf/00000000000000000000000000 000000/ef4625a9db3003f1ca25751500066d48?OpenDocument (accessed 16 June 2014).

McLelland M (2013) Ethical and legal issues in teaching about Japanese Popular culture to undergraduate students in Australia. Electronic Journal of Contemporary Japanese Studies, 13 (2). Available at: http://www.japanesestudies.org.uk/ejcjs/vol13/iss2/mclelland.html (accessed 13 January 2014).

McLelland, M (2011) Australia's child-abuse materials legislation, internet regulation and the juridification of the imagination. International Journal of Cultural Studies 15 (5): 467-83.

McLelland M and Yoo S (2007) The international yaoi Boys' Love fandom and the regulation of virtual child pornography: The limitations of current legislation. Sexuality Research and Social Policy 4 (1): 93-104. 
Nair A (2010) Real porn and pseudo porn: The regulatory road. International Review of Law, Computers and Technology 24(3): 223-232.

Newcastle Herald (2009) Man fined for downloading Simpsons cartoon porn, March 13. Available at: http://www.theherald.com.au/story/493899/man-fined-for-downloadingsimpsons-cartoon-porn/ (accessed 8 May 2013).

Orbaugh S (2010) Girls reading Harry Potter, girls writing desire: Amateur manga and shôjo reading practices. In Aoyama T and Hartley B (eds) Girl Reading Girl in Japan. Oxon: Routledge, pp. 174-85.

Ost S (2009) Child Pornography and Sexual Grooming: Legal and Societal Responses. Cambridge: Cambridge University Press.

Pendleton, M and Serisier, T (2009) Beyond the desire for law: Sex and crisis in Australian feminist and queer politics. Australian Feminist Law Journal 31(77-98).

R. v. Sharpe, [2001] 1 S.C.R. 45, 2001 SCC 2. Available at: http://scc-csc.lexum.com/scccsc/scc-csc/en/item/1837/index.do (accessed 16 June 2014).

Palfrey J and Gasser U (2008) Born Digital: Understanding the First Generation of Digital Natives. New York: Basic Books.

Pallotta-Chiarolli M (2010) Border Sexualities: Border Families in Schools. Lanham: Rowman and Littlefield.

Plummer K (2010) Generational sexualities, subterranean traditions, and the hauntings of the sexual world: Some preliminary remarks. Symbolic Interaction 33 (2): 163-90.

Plummer K (2003) Intimate Citizenship: Private Decisions and Public Dialogues. Seattle: University of Washington Press.

Sahlfeld M (2010) The protection of minors and its effect on cultural diversity: An example of content regulation in digital game environments. In Graber C B and Burri-Nenova M (eds) Governance of Digital Game Environments and Cultural Diversity. Cheltenham: Edward Elgar, pp. 202-36. 
Saito T (2007) Otaku sexuality. In Bolton C, Csicsery-Ronay I Jr. and Tatsumi T (eds) Robot Ghosts and Wired Dreams: Japanese Science Fiction from Origins to Anime. Minneapolis: University of Minnesota Press, pp. 222-49.

Simpson B (2013) Challenging childhood, challenging children: Children's rights and sexting. Sexualities 16(5/6): 690-709.

Thorn M (2004) Girls and women getting out of hand: The pleasure and politics of Japan's amateur comics community. In Kelly W (ed.) Fanning the Flames: Fans and Consumer Culture in Contemporary Japan. Albany: State University of New York Press, pp. 169-87.

Tosenberger C (2008) Homosexuality at the online Hogwarts: Harry Potter slash fanfiction. Children's Literature 36:185-207.

Tresca D (2014) Spellbound: An analysis of adult-oriented Harry Potter fanfiction. In Barton KM and Lampley JM (eds) Fan Culture: Essays on Participatory Fandom in the $21^{\text {st }}$ Century. Jefferson: McFarland and Co, pp. 36-45.

Turk T (2011) Metalepsis in fan vids and fan fiction. In Kukkonen K and Klimek S (eds) Metalepsis in Popular Culture. Berlin: Walter de Gruyter \& Co, pp. 83-103.

Walton M (2005) Possession of child pornography. NSW Council for Civil Liberties Background Paper. Available at:

http://www.nswccl.org.au/docs/pdf/bp2\%202005\%20Possess\%20Child \%20Porn.pdf (accessed 12 December 2013).

Waskul D and Martin J (2010) Now the orgy is over. Symbolic Interaction 33 (2): 297-318. WHILEY v R (2010) NSWCCA 53. Available at: http://www.austlii.edu.au/au/cases/nsw/NSWCCA/2010/53.html (accessed 16 June 2014). Williams B and Zenger A (2012) Introduction: popular culture and literacy in a networked world. In Williams B and Zenger A (eds) New Media Literacies and Participatory Popular Culture across Borders. Oxon: Routledge, pp. 1-14.

Wood A (2013) Boys love anime and queer desires in convergence culture: Transnational fandom, censorship and resistance. Journal of Graphic Novels and Comics 4 (1): 44-63. 
Wood A (2011) Choose your own queer erotic adventure: Young adults, boys' love computer games and the sexual politics of visual play. In Abate MA and Kidd K (eds) Over the Rainbow: Queer Children's and Young Adult Literature. Ann Arbor: University of Michigan Press, pp. 354-78.

Young, G and M. Whitty (2012) Transcending Taboos: A Moral and Psychological Examination of Cyberspace. New York: Routledge.

Mark McLelland is an Australian Research Council Future Fellow and Professor of Gender and Sexuality Studies at the University of Wollongong. He has written extensively on gender and sexuality in Japanese popular culture, most recently in the book, Love, Sex and Democracy in Japan during the American Occupation (PalgraveMacmillan 2012). He is coeditor (with Vera Mackie) of The Routledge Handbook of Sexuality Studies in East Asia (Routledge 2015).

\footnotetext{
'Research for this article was supported by Australian Research Council grant FT120100388.
} 